\title{
ANALISIS GETARAN ROTASIONAL TEREDAM SISTEM BATANG DAN PEGAS TORSIONAL UNTUK DIKEMBANGKAN SEBAGAI MODEL FLUKTUASI EKONOMI
}

\author{
Nani Yuningsih ${ }^{1, \text { a) }}$, Kunlestiowati Hadiningrum², b), Sardjito ${ }^{3, c)}$ \\ 1,2,3 Politeknik Negeri Bandung, Jl. Terusan Gegerkalong Hilir, Ds. Ciwaruga, Kotak Pos 1234, Bandung \\ Email: a)nani.yuningsih@polban.ac.id, b)kunpolban@yahoo.co.id, c)sardjito@polban.ac.id
}

\begin{abstract}
Abstrak
Sistem getaran bebas yang ideal ditandai dengan gerak bolak balik periodik dengan besar amplitudo yang tetap. Pada kenyataannya, terhadap sistem getaran semacam ini, bekerja gaya luar yang akan meredam getaran sehingga amplitudonya akan berkurang secara terus menerus. Pada getaran teredam, selain amplitudo berubah, frekuensinya juga akan berbeda dengan frekuensi getaran bebas. Telah diteliti fenomena getaran rotasional batang homogen yang melekat pada pegas torsional dan mengalami redaman karena adanya gesekan udara baik secara teoritis maupun secara empiris. Pada dasarnya karakteristik getaran rotasional mirip dengan getaran translasi. Peubah yang diamati adalah amplitudo sudut simpangan serta perioda getar. Pengukuran dilakukan dengan bantuan kamera video dan pencacah digital. Hasil pengamatan empiris memperkuat solusi dari persamaan diferensial yang diperoleh melalui analisis teoritis terhadap sistem getaran teredam. Hasil penelitian terhadap sistem getaran batang dan pegas yang bersifat mekanik ini dikembangkan untuk meninjau fenomena fluktuasi ekonomi yang terjadi di Indonesia, dengan menggunakan analogi antara peristiwa fisika dengan peristiwa ekonomi (fisika ekonomi).
\end{abstract}

Kata-kata kunci: getaran rotasional, pegas torsional, getaran teredam, fisika ekonomi.

\begin{abstract}
The ideal free vibration system is characterized by periodic oscillation motion with fixed amplitude. In fact, towards this kind of vibration system, there is an external force that will dampen the vibration so the amplitude will be decreased continuously. In damped vibrations, in addition to amplitude change, the frequency will also be different from the frequency of free vibration. It has been observed the phenomenon of rotational homogeneous rods attached to torsional spring and occurs damping due to air friction both theoretically and empirically. Basically rotational vibration characteristics are similar to translational vibrations. The observed variables are the deviation angle of the amplitude and the vibration period. Measurements are done by video camera and digital counter. The empirical observations reinforce the solution of the differential equations obtained by theoretical analysis of the damped vibration system. The result of the research on the mechanical rod and spring vibration system was developed to observe the phenomenon of economic fluctuation occurring in Indonesia, using the analogy between physics phenomenon and economic phenomenon (econophysics).
\end{abstract}

Keywords: rotational vibration, torsional spring, econophysics. 


\section{PENDAHULUAN}

Sejak tahun 1977 dunia ilmu pengetahuan mengenal satu cabang ilmu yang disebut "Fisika Ekonomi”(econophysics). Kata kunci ilmu ini adalah fluktuasi yang selalu muncul pada setiap kegiatan ekonomi yang nyata. Berbagai gejala ekonomi yang menyangkut aliran uang dan perubahan harga yang bersifat rumit dapat dianalisis oleh metoda yang dikembangkan dalam studi fisika statistik[1].

Dalam konsep dasar ekonomi, keseimbangan antara permintaan dan persediaan dapat dianalogikan dengan sistem getaran tanpa fluktuasi gaya luar. Namun dalam keadaan sesungguhnya, beberapa variabel ekonomi merupakan besaran yang berfluktuasi dianalogikan dengan sistem getaran mekanik pegas elestik tanpa fluktuasi gaya luar.

Tinjauan sistem pegas dengan beban bermassa dapat menghasilkan gerak getaran yang ditandai dengan berubahnya posisi beban terhadap waktu mengikuti fungsi osilasi harmonik logaritmik. Jika massa beban konstan, maka fungsi posisi terhadap waktu akan berbentuk harmonik murni (sinus dan/atau cosinus). Sedangkan massa beban yang berubah secara linier mengakibatkan terjadinya relaksasi perioda getaran. Model pegas berbeban dapat digunakan untuk mendeskripsikan peristiwa dinamika nilai tukar rupiah terhadap valuta asing, khususnya bila ada gangguan yang cukup berarti yang berakibat pada terjadinya lonjakan $[2,3,4]$.

Secara fisis osilasi dapat diklasifikasikan sebagai getaran bebas, getaran teredam, getaran paksa, serta getaran paksa teredam.

\section{Getaran Rotasional Bebas}

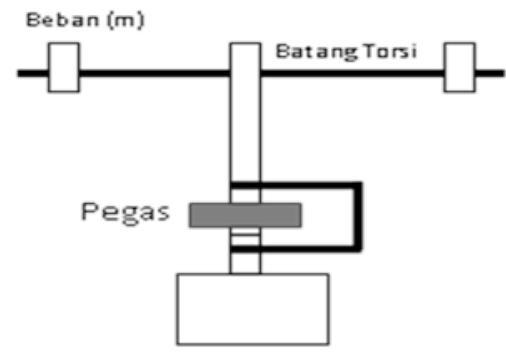

Persamaan gerak rotasi suatu benda dengan momen inersia I akan memiliki momen gaya sebesar

$$
\tau=I \alpha
$$

dan jika benda benda tersebut diletakkan pada pegas yang memiliki konstanta pegas $\mathrm{k}$ dan disimpangkan dengan sudut $\theta$, besarnya momen gaya adalah sebesar

$$
\tau=k \theta
$$

Dari persamaan (1) dan (2) dapat diperoleh

$$
\alpha=\frac{d^{2} \theta}{d t^{2}}=-\frac{k}{I} \theta
$$

Sehingga dari persamaan diferensial tersebut, jika

$$
\frac{d^{2} \theta}{d t^{2}}=-\omega_{O}{ }^{2} \theta
$$

Diperoleh 


$$
\omega_{o}=\sqrt{\frac{k}{I}}=\text { frekuensi alamiah }
$$

\section{Getaran Rotasional Teredam}

Getaran rotasional teredam terjadi bila sistem getaran bebas dipengaruhi juga oleh gaya peredam (gaya gesekan, hambatan) yang umumnya bergantung pada kecepatan gerak; artinya besar gaya peredam bergantung pada besar kecepatan sedang arahnya berlawanan[5]. Hal ini berakibat makin kecilnya simpangan pegas untuk perioda berikutnya. Persamaan getaran rotasional teredam memenuhi persamaan (4).

$$
I\left(\frac{d^{2} \theta}{d t^{2}}\right)+c \frac{d \theta}{d t}+k \theta=0
$$

Dengan c adalah koefisien redaman dan $\gamma=\mathrm{c} / 2 \mathrm{I}$ adalah efek redaman. Jika $\omega_{O}{ }^{2}=\frac{k}{I}$ maka persamaan (4) dapat dituliskan dalam bentuk:

$$
\ddot{\theta}+2 \gamma \dot{\theta}+\omega_{o}^{2}=0
$$

Solusi persamaan ini tergantung pada besarnya redaman. Bila redaman cukup kecil, solusinya berbentuk bilangan kompleks, sedang sistem masih akan bergetar, namun pada akhirnya akan berhenti. Keadaan ini disebut kurang redam atau redaman kecil (under damping), dan merupakan kasus yang paling mendapatkan perhatian dalam analisis vibrasi. Bila peredaman diperbesar sehingga mencapai titik saat sistem tidak lagi berosilasi, kita mencapai titik redaman kritis (critical damping). Solusi umum pendekatan persamaan (4) dapat dituliskan sebagai berikut:

$$
\theta(t)=e^{-\gamma t} \cos (\omega t-\theta)
$$

Bila peredaman ditambahkan melewati titik kritis ini sistem disebut dalam keadaan lewat redam atau redaman besar (over damping). Untuk kondisi lewat redam dan redaman kritis, solusi persamaan diferensial di atas berbentuk bilangan nyata yang mengecil secara eksponensial terhadap waktu.

Solusi sistem getaran dengan redaman kecil (kurang redam) pada model massa-pegas-peredam adalah

$$
\theta(t)=\theta e^{-\varsigma} \omega_{n} t \cos \left(\sqrt{\left(1-\varsigma^{2}\left(\omega_{n} t-\phi\right)\right)}\right)
$$

$$
\text { dengan } \omega_{n}=2 \pi f_{n} \text {. }
$$

Dari solusi tersebut perlu diperhatikan dua hal yaitu faktor eksponensial dan fungsi cosinus. Faktor eksponensial menentukan seberapa cepat sistem teredam. Semakin besar nisbah redaman, semakin cepat sistem teredam ke titik nol. Fungsi cosinus melambangkan osilasi sistem, namun frekuensi osilasi berbeda daripada kasus tidak teredam. Jadi frekuensi getaran teredam berbeda dengan frekuensi getaran bebas. 


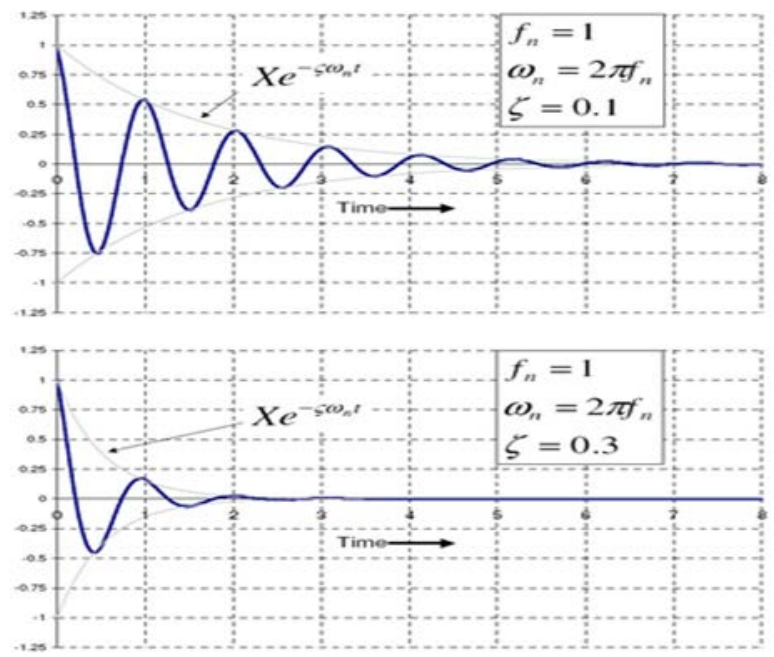

GAMBAR 1. Grafik simpangan terhadap waktu untuk getaran teredam [2]

\section{METODE PENELITIAN}

Metode yang digunakan dalam penelitian ini adalah metode analisis deskriptif. Instrumen penelitian terdiri dari perangkat alat untuk mengamati amplitudo sudut simpangan dan perioda getar. Digunakan dua jenis batang homogen yaitu batang berbeban dan batang tanpa beban. Pemilihan kedua benda ini berdasarkan pada kemudahan mengamati gerak osilasinya. Batang tersebut dipasang pada pegas torsional dengan konstanta pegas $0,024 \mathrm{~N} / \mathrm{m}$. Perubahan amplitudo terbaca pada kamera yang dipasang di atas alat, sedangkan periodanya diukur dengan menggunakan digital counter/pencacah digital.

GAMBAR 2 (a) merupakan perangkat alat yang digunakan untuk mendapatkan data perubahan amplitude dan perioda getar batang homogen tanpa beban. GAMBAR 2 (b) merupakan perangkat alat yang digunakan untuk mendapatkan data perubahan amplitudo dan perioda getar batang homogen berbeban. Panjang, massa batang, dan massa beban (2 buah) masing-masing $60 \mathrm{~cm}, 176,5$ gram, dan 238 gram dengan beban diletakkan pada jarak $25 \mathrm{~cm}$ dari sumbu putar.

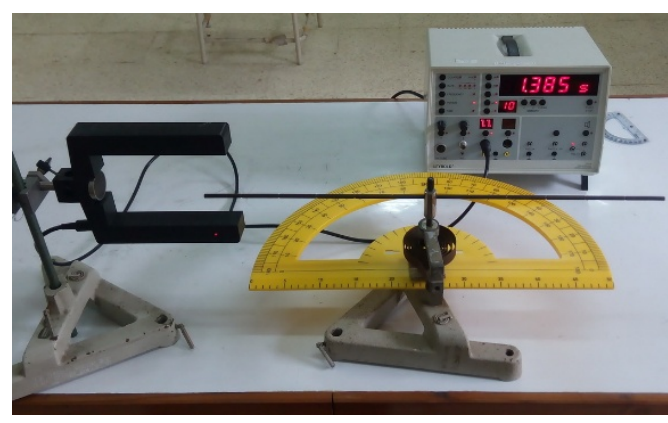

(a)

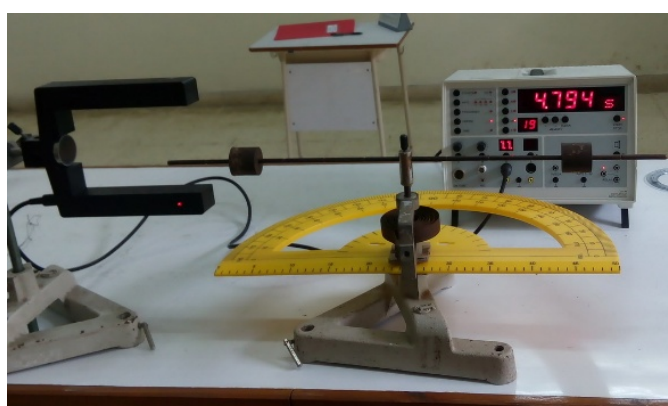

(b)

GAMBAR 2. Perangkat alat pengukur amplitudo dan waktu untuk (a) batang tanpa beban dan (b) batang berbeban 
Spesifikasi perangkat alat yang digunakan dapat dilihat pada Tabel 1.

TABEL 1. Spesifikasi perangkat benda yang digunakan

\begin{tabular}{clcc}
\hline No. & \multicolumn{1}{c}{ Spesifikasi } & Batang tanpa beban & Batang berbeban \\
\hline 1. & Massa $(\mathrm{kg})$ & 0,1765 & 0,1765 \\
2. & Panjang $(\mathrm{m})$ & 0,6 & 0,6 \\
3. & Massa beban $(\mathrm{kg})$ & - & 0,238 \\
4. & Letak beban dari sumbu putar $(\mathrm{cm})$ & - & 0,25 \\
5. & Sudut simpangan awal (rad) & 1,57 & 1,57 \\
\hline
\end{tabular}

Hasil pengamatan empiris dibandingkan dengan solusi persamaan diferensial yang diperoleh melalui analisis teoritis terhadap sistem getaran teredam.

\section{HASIL DAN PEMBAHASAN}

Sebuah benda homogen apabila diletakkan pada pegas torsi dan disimpangkan, maka benda akan berosilasi bebas dengan perioda T. Jika benda memiliki momen inersia I dan pegas memiliki konstanta pegas k maka besarnya perioda getar batang tersebut dapat dituliskan sebagai berikut:

$$
T=2 \pi \sqrt{\frac{I}{k}}
$$

Pada penelitian ini telah dibahas getaran rotasional teredam untuk sistem benda berbentuk batang homogen tanpa beban dan batang homogen berbeban. Yang berlaku sebagai peredam pada kasus ini adalah gaya gesekan udara. Hal ini dapat diamati dari amplitude osilasi yang makin lama semakin berkurang dan pada akhirnya osilasi akan berhenti. Batang homogen berbeban memiliki momen inersia lebih besar $\left(I=\frac{1}{12} m L^{2}+2 M r^{2}\right)$ dibanding dengan momen inersia batang tanpa beban $\left(I=\frac{1}{12} m L^{2}\right)$. Dari persamaan (8) dapat dilihat bahwa perioda sebanding dengan momen inersia, sehingga perioda batang berbeban lebih besar dari perioda batang tanpa beban. Hal ini menunjukkan bahwa waktu yang diperlukan untuk bergetar batang berbeban memerlukan waktu lebih lama dibanding waktu yang diperlukan untuk bergetar batang tanpa beban untuk jumlah getaran yang sama.

Dengan simpangan sudut awal 1,57 rad diperoleh grafik simpangan sudut untuk batang tanpa beban dan batang berbeban masing-masing seperti tampak pada Gambar 3 dan Gambar 4.

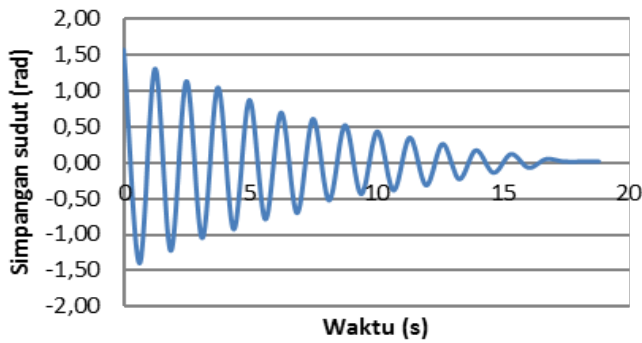

(a)

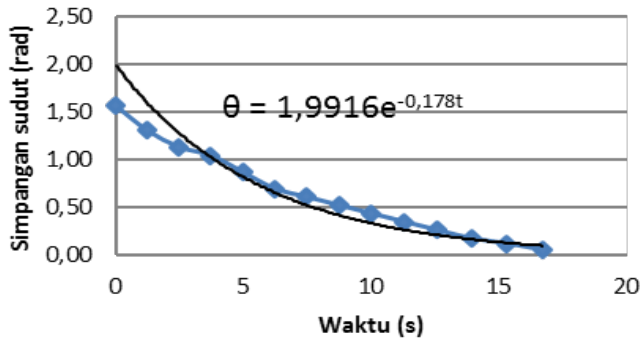

(b)

GAMBAR 3. Grafik (a) simpangan sudut terhadap waktu batang tanpa beban dan (b)hasil ektrapolasi 


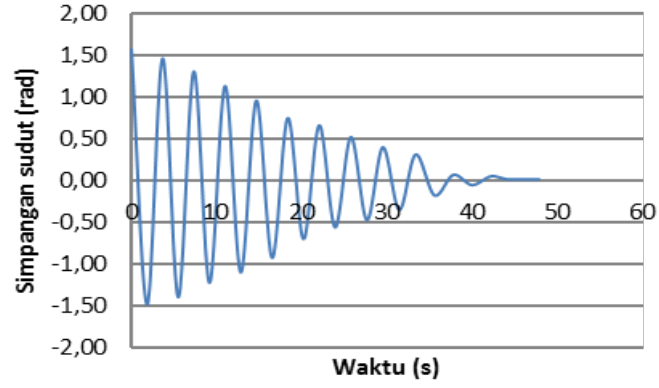

(a)

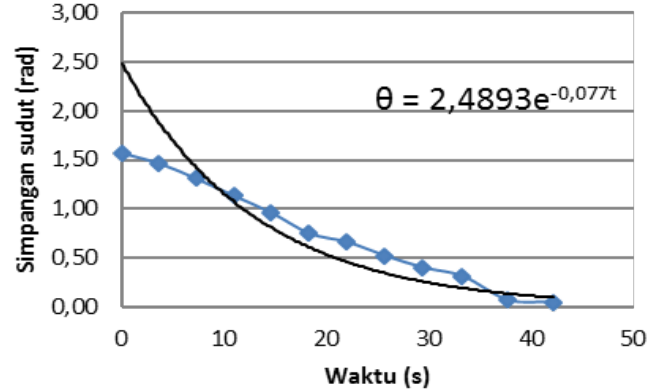

(b)

GAMBAR 4. Grafik (a) simpangan sudut terhadap waktu batang berbeban dan (b) hasil ektrapolasi

Dari hasil pengukuran secara empiris diperoleh data perioda rata-rata batang homogen berbeban sebesar 3,768 s, sedangkan perioda rata-rata batang homogen tanpa beban sebesar 1,274 s . Hal ini sesuai dengan persamaan (8) yaitu persamaan untuk menghitung perioda secara teori yaitu semakin besar momen inersia suatu benda maka perioda getar akan semakin besar.

Selain menganalisis besar perioda getar, pada penelitian ini juga dilakukan analisis efek redaman. Efek redaman $\left(\gamma=\frac{c}{2 I}\right)$ berbanding terbalik dengan massa. Untuk getaran rotasional, massa analogi dengan momen inersia, sehingga efek redaman dalam hal ini berbanding terbalik dengan momen inersia benda yang berosilasi.

Batang homogen tanpa beban memiliki efek redaman sebesar 0,178 sedangkan batang homogen berbeban sebesar 0,077. Dengan demikian batang homogen berbeban memerlukan waktu osilasi lebih lama untuk berhenti dibanding dengan batang berbeban.

Apabila dikaitkan dengan kondisi ekonomi Indonesia, terdapat kemiripan antara getaran rotasional batang pada pegas torsional ini dengan salah satunya analogi dengan fluktuasi nilai tukar rupiah. Dimana efek redaman dapat dianalogikan dengan upaya (kebijakan) pemerintah untuk menstabilkan nilai tukar seperti Intervensi BI, pinjaman luar negeri, perubahan suku bunga, dan lain lain.

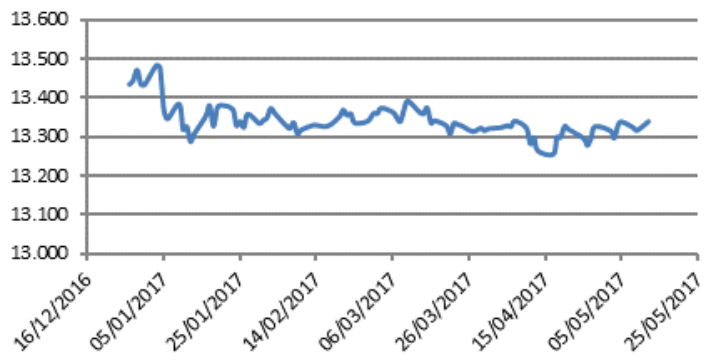

GAMBAR 5. Kurs tengah BI periode Desember 2016-Mei 2017

Pada pertengahan bulan Desember 2016, rupiah mengalami penguatan. Hal ini terjadi kaena pada saat itu mata uang negara-negara berkembang menguat seiring dengan kenaikan harga minyak dunia setelah OPEC dan anggota non OPEC mencapai kesepakatan pertama mereka sejak 2001 untuk bersama-sama mengurangi produksi guna mengatasi membanjirnya pasokan global. Pada akhir Desember 2016 rupiah kembali melemah. Salah satu penyebab melemahnya rupiah pada periode 
tersebut adalah isu berakhirnya periode 2 tax amnesty yang realisasinya belum mencapai target perbaikan ekonomi Indonesia [6].

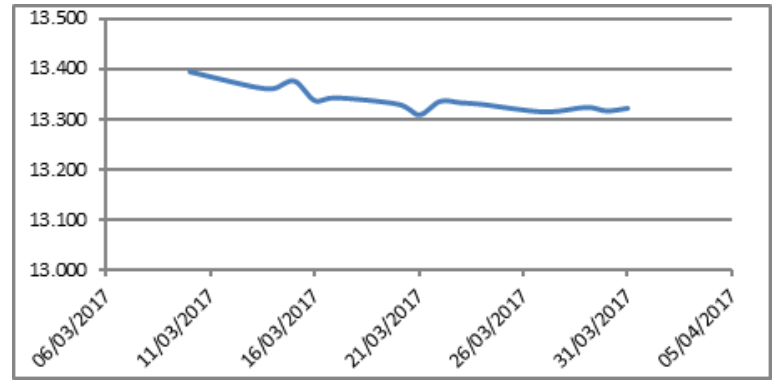

GAMBAR 6. Kurs tengah BI rupiah terhadap USD periode Maret 2017

Periode Februari- Maret 2017 relatif stabil salah satunya dengan adanya pengumuman pemerintah atas cadangan devisi negara meningkat. Peningkatan tersebut terutama dipengaruhi penerimaan devisa, antara lain berasal dari penerimaan pajak dan devisa ekspor migas bagian pemerintah, penarikan pinjaman luar negeri pemerintah, serta hasil lelang Surat Berharga Bank Indonesia (SBBI) [7]. Namun demikian pada pertengahan Februari 2017 sempat terjadi pelemahan rupiah karena adanya isu reshuffle kabinet.

Dari ulasan ekonomi dan analisis getaran rotasional batang dan pegas torsional terjadi kemiripan model. Hal ini menunjukkan bahwa fenomena peristiwa fisika dapat digunakan sebagai model fluktuasi ekonomi di Indonesia.

\section{SIMPULAN}

Model fluktuasi ekonomi Indonesia dapat dianalogikan dengan fenomena Fisika berupa getaran rotasional batang dan pegas torsional. Dari hasil analisis terdapat kemiripan antara getaran rotasional batang pada pegas torsional ini dengan salah satunya analogi dengan fluktuasi nilai tukar rupiah.

\section{UCAPAN TERIMAKASIH}

Terimakasih kepada Direktorat Riset dan Pengabdian kepada Masyarakat (DRPM) Kemenristekdikti melalui Unit Penelitian dan Pengabdian kepada Masyarakat (UPPM) Politeknik Negeri Bandung yang telah mendanai penelitian ini dan kepada rekan-rekan pengajar Fisika Terapan Polban yang telah turut berkonstribusi dalam penelitian ini.

\section{REFERENSI}

[1] H. Kunlestiowati, Sardjito, "Penerapan model kinetika pembakaran pada fenomena fluktuasi nilai valuta asing di Indonesia” Spektrum IX-2-Oktober 2002.

[2] H. Kunlestiowati, et al, "Application of Physics Phenomenon Towards The Economic Symptoms in Indonesia (Spring Oscillation Model and Rupiah Rate Exchange)”, presented at The International Conference on Islamic Economics, Management, Accounting, Business and Social Science, Proceeding ICIEMABS ISBN: 978-602-74942-0-6 Batam 2016.

[3] Hadiningrum, H. Kunlestiowati, Y. Nani, and Sardjito. "Model Osilasi Harmonik Logaritmik pada Gerak Beban dengan Massa yng Berubah Secara Linier terhadap Waktu." SIGMA-Mu 3, no. 1 (2011): 1-10. 
[4] H. Kunlestiowati, Y. Nani, and Sardjito. "Getaran sistem pegas berbeban dengan massa yang berubah terhadap waktu." In Prociding Industrial Research Workshop and National Seminar, vol. 1, pp. 31-1. 2010.

[5] Susilo, Anto, Y. Mohtar, and I. V. Viska. "Simulasi Gerak Harmonik Sederhana dan Osilasi Teredam pada Cassy-E 524000." Indonesian Journal of Applied Physics (2012) 2, no. 2 (2012): 124.

[6] A. Gideon (13 Desember 2016). Available: http://www.m.liputan6.com.

[7] A. Gideon (18 Maret 2017). Available: http://www.m.liputan6.com 